\title{
0 projeto do êxodo e a legitimidade do poder: aspectos sintomáticos da narrativa exodal a respeito da migração humana
}

\author{
The Exodus Project and the Legitimacy of Power: \\ Symptomatic Aspects of the Exodal Narrative \\ of Human Migration
}

\section{El Proyecto Éxodo y la legitimidad del poder: aspectos sintomáticos de la narrativa exodal de la migración humana}

Petterson Brey*

\begin{abstract}
RESUMO
A partir do primeiro discurso do Senhor direcionado ao povo no episódio ambientado em Êxodo 19, tendo como locação cênica o monte Sinai, pode-se perceber a pungência retórica que configura o discurso narrativo da trama exodal. As palavras do protagonista principal dessa metanarrativa evocam por meio de uma retrorreferência discursiva a reputação do Senhor - vertida em seu comportamento salvífico - para reiterar os termos da aliança que se está propondo aos hebreus, em vista do anúncio do estabelecimento de um reino de sacerdotes e uma nação santa. O arranjo pragmático, verificável a partir do substrato sintomático subjacente ao enredo, põem em contraste a legitimidade da soberania do Senhor sobre toda a terra com o exercício abusivo do poder por parte do faraó egípcio. Destarte, a intervenção divina que pôs em ação o projeto do êxodo - movida pelo grito dos oprimidos pelo sistema totalitário do Egito escravista - constitui-se como paradigma de justiça para Israel.
\end{abstract}

Palavras-chave: Projeto do êxodo; legitimidade do poder; soberania; migração; narrativas bíblicas.

\begin{abstract}
From the Lord's first speech to the people in the episode set in Exodus 19, with Mount Sinai as its scenic location, one can see the rhetorical poignancy that shapes the narrative discourse of the exodal plot. The words of the main protagonist of this metanarrative evoke by means of a discursive retro reference the reputation of the Lord - poured into his saving behavior - to reiterate the terms of the covenant that is being proposed to the Hebrews, in view of the announcement of the establishment of a kingdom of priests and A holy nation. The pragmatic arrangement, verifiable from the symptomatic substrate underlying the plot, contrasts the legitimacy of the Lord's sovereignty over the whole earth with the Egyptian pharaoh's abusive exercise of power. Thus, the divine intervention
\end{abstract}

* Doutorando e mestre em Teologia pelo PEPG/PUC-SP. Bolsista CAPES. Membro do Grupo de Pesquisa TIAT (Tradução e Interpretação do Antigo Testamento). 
that set-in motion the project of the exodus - driven by the cry of the oppressed by the totalitarian system of slaveholding Egypt - constitutes a paradigm of justice for Israel.

Keywords: Project of the exodus; legitimacy of power; sovereignty; migration; Biblical narratives.

\section{RESUMEN}

Desde el primer discurso del Señor a la gente en el episodio ambientado en Éxodo 19, con el Monte Sinaí como su ubicación escénica, se puede ver la conmoción retórica que da forma al discurso narrativo de la trama exodal. Las palabras del principal protagonista de esta evocación metanarrativa mediante una retroferencia discursiva de la reputación del Señor, vertida en su comportamiento salvador, para reiterar los términos del pacto que se propone a los hebreos, en vista del anuncio del establecimiento de un reino de sacerdotes y Una nación santa La disposición pragmática, verificable desde el sustrato sintomático subyacente a la trama, contrasta la legitimidad de la soberanía del Señor sobre toda la tierra con el ejercicio abusivo del poder del faraón egipcio. Por lo tanto, la intervención divina que puso en marcha el proyecto del éxodo, impulsado por el grito de los oprimidos por el sistema totalitario de esclavitud de Egipto, constituye un paradigma de justicia para Israel.

Palabras clave: Proyecto del éxodo; legitimidad del poder; soberanía; migración; narraciones bíblicas.

\section{Introdução}

"Vós vistes o que fiz aos egípcios, como vos levantei contra as asas de abutre, e vos trouxe a mim! Agora, se ouvirdes a minha voz e guardardes a minha aliança, sereis minha propriedade peculiar - porque toda a Terra é minha -, e me representareis como um reino de sacerdotes e uma nação santa" (Êxodo 19,4-6a). ${ }^{1}$ Eis as palavras do protagonista principal da narrativa exodal que, por meio de um discurso direto, se dirige ao povo que chegara até o Sinai depois de uma longa jornada pelo deserto, em fuga do sistema opressor do Egito escravista.

O discurso do Senhor - preâmbulo da legislação do Antigo Israel -, a partir de sua configuração retórica, conecta-se com elementos sintomáticos da trama narrada, que tratam das relações de poder, vertidas em condutas injustas, e seu impacto direto no projeto migratório do êxodo israelita. Por meio da abordagem literária, metodologicamente ajustada, da Análise Narrativa é possível perceber o contorno artístico empregado na composição do enredo em que esta cena se desenvolve. O objetivo dessa retrorreferência discursiva, feita a certos elementos que compõem a trama narrada, é contrastar a conduta do faraó egípcio com o comportamento do Senhor. De acordo com o argumento do discursista, o Senhor legitimou a sua soberania - se

\footnotetext{
${ }^{1}$ Tradução do autor a partir de: v. 4 :

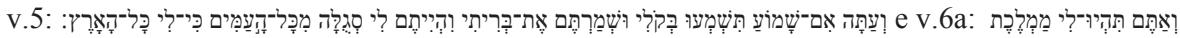

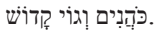


distinguindo dos reis humanos com suas divindades - agindo em favor dos vulneráveis. Destarte, a eleição de Israel se justifica, unicamente, na representação dos interesses salvíficos do soberano de toda a terra.

Assim, o corte proposto por esse pequeno estudo possui como objeto material o discurso do protagonista principal no âmbito da metanarrativa exodal e, como objeto formal, o tema da legitimidade do poder, subjacente ao substrato sintomático da trama narrada. Dentre outras temáticas que emergem do mundo narrado - tais como os elementos teológicos e cultuais que irão configurar a religião do Antigo Israel, bem como os aspectos legais que constituirão a legislação israelita -, a abordagem a seguir se restringirá às relações entre a legitimidade de soberania e o processo migratório, tendo como perspectiva a reputação evidenciada pelo comportamento daqueles que detêm o poder.

Por fim, essa reflexão crítica a respeito daquilo que se narra nessa literatura tão antiga - patrimônio literário-cultural da humanidade - pretende estabelecer um diálogo proveitoso entre a sabedoria, oriunda do que se pensa nas tradições do Pentateuco, e as questões emergentes de um dos dramas mais atuais da humanidade, o deslocamento migratório.

"Ao dialogar com o passado e com suas vozes mais marcantes é que, justamente, podem surgir, no tempo atual, resistências a quem insiste na maldade e nas posturas marcadas pela solidariedade com quem se encontra numa situação de risco ao lutar, em terras estrangeiras, por sua sobrevivência digna" (GRENZER, 2017, p. 14).

\section{Aspectos literários da narrativa exodal}

Recentes avanços no campo dos estudos bíblicos têm se beneficiado da contribuição exegética proveniente de análises literárias das narrativas bíblicas, as quais se caracterizam por uma leitura sincrônica do texto afastando-se das questões relativas ao provável ambiente originador dos supostos documentos históricos -, cuja preocupação principal é a análise da configuração literária intencionalmente empregada na edição do texto canônico (SKA, 2009, p. 140-141). Nesse tipo de leitura, o ouvinte-leitor das histórias da Bíblia Hebraica precisa ter em mente a composição artística do texto sagrado, que se configura, principalmente, de forma estética (BAR-EFRAT, 2008, p. 64-77). Destarte, a forma como os autores bíblicos se expressam impressiona os seus destinatários de um jeito que não o seriam de outra maneira (ALTER, 1985, p. 151). Porquanto, a estética do texto é tão importante quanto o seu conteúdo, pois a mensagem é, ao mesmo tempo, as duas coisas (BERLIN, 1996, p. 302). 
Uma das estratégias literárias comuns na Bíblia Hebraica - sobretudo em contextos legais -, para conduzir o ouvinte-leitor às camadas de significado mais profundas da trama, é fazer com que o narrador empreste sua voz - por meio da inserção de um discurso direto - ao legislador-protagonista (BARTOR, 2010, p. 22-84). Por meio desse recurso, diversos elementos explicativos são introduzidos para que não se perca de vista a temática do discurso narrativo (LONGACRE, 1996, p. 34, 39, 48, 49, 76), visto que, no âmbito das narrativas bíblicas, a retórica do texto ganha realce ao conectar-se com os significados implícitos e, portanto, detectáveis pelo substrato sintomático do enredo (MARGUERAT; BOURQUIN, 2009, p. 158-162). Esses quadros discursivos são pré-estabelecidos por um esquema pragmático, que pretende dar suporte retórico às intenções temáticas do autor, através de molduras sintático-gramaticais bem executadas (MILLER, 1994, p. 199-241).

O ato de fala do Senhor - em Êxodo 19,3-6a - é constituído por quatro blocos retóricos bem definidos: fundamentação, apelo, proposta e objetivo (BREY, 2019, p. 75, 76). O quadro abaixo estabelece uma perspectiva estética a respeito da configuração do discurso do Senhor:

v.5e porque toda a Terra é minha

\section{FUNDAMENTAÇÃO}

APELO

v.4a Vós vistes

v.4b o que fiz aos egipcios,

v.4c como vos levantei contra as asas de abutre,

v.4d e vos trouxe a mim!

v.5a Agora,

v.5b se ouvirdes a minha voz

v.5c e guardardes a minha aliança,

v.5d sereis minha propriedade peculiar,

OBJETIVO

v.6a e me representareis como um reino de sacerdotes e uma nação santa.

Cada uma dessas seções do discurso constrói uma linha de comunicação secundária, acessível através de conexões com o contexto mais amplo do discurso (HOUTMAN, 1996, p. 424, 425). Tomando-se a configuração retórica do discursista de trás para frente, tem-se: (a) em v.6a, a eleição do povo como representante da justiça do Senhor diante dos reinos da terra, como objetivo; (b) em v.5a-d, a persuasão do povo para aceitar a aliança 
que os tornará propriedade do senhor, como proposta; (c) em v.4a-d, a reputação do Senhor, demonstrada pela sua ação salvífica e juízo contra o regime opressor egípcio, como apelo; e, (d) em v.5d, a soberania do Senhor diante de toda a terra, como fundamentação (BREY, 2019, p. 76).

O Senhor propõe uma aliança com seu povo, para que eles o representem diante das nações da terra através de um comportamento exemplar, assim como ele mesmo se comportou diante da opressão violenta desferida pelo faraó egípcio (PROPP, 2006, p. 159, 160). No cerne dessa questão está a legitimidade da ação divina contra o Egito, bem como de constituir Israel como promotor de sua justiça diante de todos os povos (PIXLEY, 1987 , p. 135-137). Ser propriedade peculiar do Senhor, pois, refere-se a um projeto de parceria, que ao mesmo tempo que é um privilégio, é uma responsabilidade (FISCHER; MARKL, 2009, p. 214, 215).

Em seu discurso, o Senhor fundamenta suas ações no fato de que ele é soberano - v.5e -, mas, ao apelar que os israelitas contemplem suas ações salvíficas por meio de uma retrorreferência ao seu comportamento diante da injustiça - v.4a-d -, ele está, também, legitimando a sua soberania (HOUTMAN, 1996, p. 424, 425). Em contraste com faraó, que pretendia ser soberano por meio da exploração escravista, Senhor estabelece um padrão de justiça que não reconhece a legitimidade de nenhum projeto de poder opressor (DURHAM, 1987, p. 258-262). De acordo com suas palavras, a reputação de um soberano é legitimada pelo seu comportamento determinado a garantir a dignidade daqueles que não podiam agir em defesa própria (GRENZER, 2007, p. 13).

\section{Elementos sintomáticos no mundo narrado}

Como dito anteriormente, as linhas de comunicação do discurso do protagonista com a textura argumentativa da narrativa como um todo constituem-se como a principal chave de leitura de uma obra literária (ROBBINS, 2012, p. 21-29). "A busca pelo sentido de um discurso pode seguir quatro instâncias distintas de significado, sendo que a modulação entre elas se dá pelo nível de abstração empregado pelo ouvinte-leitor" (BREY, 2018b, p. 171). Em ordem crescente de complexidade, portanto, as camadas de significado de uma narrativa vão do nível (1) referencial, passando para o nível (2) explícito e, também, pelo nível (3) implícito, para que, finalmente, atinja o nível (4) sintomático da história narrada. As duas primeiras instâncias de significado são auto evidentes, visto que a primeira corresponde ao próprio relato dos fatos e a segunda são às explicações que o autor insere dentro do próprio texto. 
Entretanto, os níveis (3) e (4) constituem-se como linhas de comunicação secundária, em que o autor estabelece conexões com o contexto mais amplo do discurso narrativo (BROWN; YULE, 2012, p. 191-200, 223226, 231-233). É, portanto, através dessa segunda linha de comunicação discursiva que o ouvinte-leitor atento entra em contato com as camadas de significado mais profundas da narrativa. Elementos implícitos são explicações que o autor deixa a entender, como se fossem pistas a serem seguidas no processo interpretativo. O substrato sintomático, por sua vez, corresponde aos aspectos presentes na descrição do próprio mundo narrado. Assim, para que o ouvinte-leitor tenha acesso aos temas tratados numa narrativa, este precisa fazer um processo de imersão no mundo narrado, em busca de identificar os motivos e os sintomas destes, que funcionam como os motores narrativos de uma história (GRENZER, 2007, p. 14; BREY, 2019, p. 78-107).

O contexto imediato do discurso do protagonista da trama exodal refere-se à história de um Deus que reprova a opressão e que age em favor dos oprimidos, dando-se a conhecer a eles através de um sistema jurídico que, em realidade, representa o seu próprio caráter (CASSUTO, 1967, p. 226, 227; CRÜSEMANN, 2002, p. 11-14). Esse enredo, entretanto, se desenvolve tendo como pano de fundo questões migratórias que estão atreladas a sistemas de poder, os quais ora agem com misericórdia e justiça, ora com opressão e violência. O que parece estar em constante contraste na metanarrativa exodal, no que se refere à legitimidade do poder, é a reputação daqueles que se propõem a exercer a soberania. Os processos migratórios, com suas causas e consequências, no entanto, parecem corresponder ao teste que legitima ou não um soberano, a depender de seu comportamento em relação aos vulneráveis.

\section{A legitimidade do poder e o projeto do êxodo}

"O contexto geopolítico do mundo narrado a partir do segundo livro do Pentateuco é, à primeira vista, muito diferente da atual configuração sociocultural e política, no entanto, certas familiaridades podem ser observadas" (BREY, 2018b, p. 166, 167), sobretudo no que tange às questões que emergem do deslocamento migratório e às relações de poder e soberania. Ademais, "a história do êxodo é um forte paradigma do alcance da liberdade como um dom de Deus e compromisso do ser humano. As tradições bíblicas apresentam uma reflexão que pode ser reconhecida, de forma igual, por ouvintes-leitores diferentes" (FERNANDES; GRENZER, 
2011, p. 6, 8). Destarte, ainda hoje, as narrativas da Bíblia Hebraica desafiam a humanidade - mesmo por questões tão antigas - a desenvolver um espírito de fraternidade universal que tenha em mente que todos os seres humanos são migrantes na terra, cujo soberano é o Senhor (ALTEMEYER JUNIOR, 2016, p. 191-197).

\section{A soberania do Senhor vertida em seu comportamento}

$\mathrm{O}$ apelo do protagonista principal da trama relatado pela história do êxodo - em seu discurso sinaítico (v.4a-d) -, para que o povo contemple suas ações salvíficas em progressão pretérita, constitui-se como um vestígio interpretativo que reflete a estratégia literária pela qual o arco narrativo desse personagem foi desenvolvido ao longo da metanarrativa do êxodo (BREY, 2019, p. 129-131). O comportamento misericordioso e justo do Senhor ao longo do processo exodal revela paulatinamente o seu caráter (CHILDS, 1991, p. 366; HOUTMAN, 1996, p. 424, 425), que será, finalmente, transcrito em forma de legislação (CRÜSEMANN, 2002, p. 11-14). O libertador dos hebreus se dá a conhecer ao seu povo como um Deus que se irrita com a injustiça e age contra a opressão (GRENZER, 2007, p. 13; BREY, 2019, p. 132).

Na metáfora das asas de abutre (v.4c), o Senhor convida seus ouvintes a contemplar seu cuidado e sua proteção enquanto os levou a enfrentar um dos maiores poderes da antiguidade - o faraó com seu exército e suas divindades -, o qual, por sua vez, teve seu poder destruidor subvertido pelo poder do Senhor (GRENZER; BREY, 2017, p. 347-360). Essa imagem, que sumariza a maneira como o Senhor subverteu a fragilidade em força, é, em sentido didático, uma expressão do comportamento divino diante da opressão. Ao dar ouvidos ao grito de dor dos israelitas, logo no início da narrativa exodal (Êxodo 2,23-25), o Senhor se apresenta na grande narrativa como um Deus atento ao grito dos injustiçados, que responde o clamor de quem grita por ele e age em favor dos vulneráveis (GRENZER, 2014b, p. 19-34).

Destarte, a autorrevelação do Senhor no Sinai diz respeito a um Deus que quer ser conhecido por seu povo, o qual ele atrai para uma relação de parceria, fiada pela sua própria reputação que é vertida em ações salvíficas (FOKKELMAN, 1987, p. 62, 63). No âmbito da retórica discursiva do Senhor, essa estrutura comportamental do legislador-protagonista é propositalmente performativa, visto que a eleição de Israel carrega em si a exigência de se comportar ao modo de seu libertador (SARNA, 1991, 
p. 104). Assim como o Senhor não legitima sua soberania pelo abuso de poder - pelo contrário, exerce seu poder de soberano como legítimo defensor dos vulneráveis -, o povo eleito deve abster-se de concepções exclusivistas e totalitárias (DOZEMAN, 2009, p. 445, 446).

\section{A opressão violenta de faraó e o êxodo israelita}

No âmbito da narrativa exodal, o Egito assume um status simbólico de antagonismo com Deus e seu povo - como é especialmente sublinhado nas feições representativas adquiridas em Êxodo 1-15 -, que tem muito mais a ver com o comportamento do faraó do que com uma disputa étnica (KESSLER, 2002, p. 109-115). Ademais, nas seções preliminares da trama do êxodo israelita, o ouvinte-leitor foi informado que numa época de escassez de alimentos - um dos principais motivos para o movimento migratório no mundo em todos os tempos - a família patriarcal encontrou refúgio no Egito (GRENZER, 2007, p. 33). Enquanto o faraó manifestava misericórdia e justiça - simbolizadas em sua concessão de poderes a José (um imigrante) -, o Senhor aprovava o governo dele, abençoando o Egito com prosperidade (BREY, 2019, p. 114-116).

É, no entanto, quando - depois de várias gerações - o soberano egípcio passa oprimir o povo de ascendência estrangeira, que o Senhor, movido pelo grito de angústia dos vulneráveis, reprova e age em favor dos injustiçados (CASSUTO, 1967, p. 226, 227). Justificando-se pelo argumento que propagandeava que os egípcios passariam necessidades caso continuassem a permitir que os estrangeiros pilhassem suas riquezas, o faraó passou, gradativamente, a cercear os direitos dos hebreus até que chegasse ao ponto de tê-los como escravos e, assim, obter lucro as custas de uma opressão cada vez mais violenta (GRENZER, 2014a, p. 141-163). Foi, por conseguinte, a obstinada recusa faraônica em acatar os termos da intervenção divina - através de Moisés -, visando a libertação do povo, que levou o sistema opressor de poder à destruição (DOZEMAN, 2009, p. 442, 443).

O povo hebreu, que chegou ao Egito por meio de um processo migratório em fuga da fome, se vê, agora, obrigado a deixar a terra que o acolheu em virtude da mentalidade que norteia o sistema de poder vigente (BREY, 2019, p. 143-147). Nesse contexto, a intervenção divina motivada pelo grito dos oprimidos, que dá início ao êxodo israelita, não apenas liberta o povo da escravidão, mas, também, liberta o próprio Egito da ideologia nefasta que norteava o sistema de poder de faraó (DURHAM, 
1987, p. 162). Assim, as razões que ilegitimaram a soberania faraônica, deveriam ser totalmente abstidas por aqueles que passariam a ser um modelo de nação diante dos povos de toda a terra (SARNA, 1991, p. 104).

\section{Considerações finais}

$\mathrm{Na}$ atualidade uma das questões migratórias mais controvertidas tem a ver com o tema da religião, visto que além de constituir-se como motivo de discriminação e perseguição - no caso das vítimas -, ela tem se tornado, também, estribo para sistemas opressores de poder, que perseguem e discriminam minorias (MOREIRA, 2017, p. 31-45). "Uma vez que não há nenhum sinal de que a atual dinâmica migratória intensificada está se acalmando, estudiosos da religião devem se preparar para um futuro trabalhoso" (USARSKI, 2016, p. 82). Nesse ínterim, é importante salientar que a religião - para que possa deixar de ser antagonista e passe a ser protagonista - deve afastar-se de assumir o papel de alicerce de sistemas de poder que, formalmente ou informalmente, segregam e legitimam a opressão e a violência.

Alternativamente, a religião deve assumir o papel de

"mediadora no diálogo entre os atores envolvidos em casos de violação de direitos humanos" [...], já que "a religião como um bem humano básico, possa ser, agora e no futuro, o único elo em comum da humanidade, uma linguagem universal entre todas as sociedades multiculturais da pós-modernidade" (BREY, 2018a, p. 20).

Assim, a voz que emana das antigas narrativas bíblicas fornece à humanidade contemporânea uma mensagem de sensatez. No âmbito da religião do Antigo Israel a legitimidade do poder está intimamente atrelada à ação em prol da justiça. Portanto, na esfera dos movimentos migratórios, a religião se legitima por estar em ação contra a opressão, nunca como causa.

Discursos político-ideológicos que, no intuito de legitimarem-se perante a consciência coletiva da população contemporânea, buscarem fundamentação ético-moral nas páginas da Bíblia Sagrada, não podem, em hipótese alguma, dissonar da reflexão promovida pelo discurso narrativo que conta as suas histórias. Destarte, qualquer referência ao texto bíblico que promova ideias que por ele sejam consideradas ilegítimas devem ser, desde o momento em que foram feitas, reputadas como produto da mesma manipulação ideológica condenada pelas narrativas bíblicas, como por exemplo, a trama abordada no presente estudo. Sistemas ilegítimos de poder parecem, desde a perspectiva das histórias narradas na Bíblia Hebraica, 
tentar ludibriar as pessoas, se fazendo parecer genuinamente autênticos por meio de discursos que pretendem garantir a seguridade da soberania estatal em prol do bem comum, mesmo que isso signifique, invariavelmente, a violação dos direitos daqueles que menos têm possibilidade de fazer sua voz ser ouvida, como é o caso, por exemplo, dos migrantes.

A metanarrativa exodal, em seu substrato sintomático, retrata o desenvolvimento de uma teoria de poder que muito bem pode encontrar paralelos no comportamento de inúmeros modelos de supremacia da história recente da humanidade. O faraó egípcio, estribado no poder proveniente de sua posição de liderança formal, não dissimulou seus esforços para subjugar violentamente os hebreus a seu sistema escravista de governo. O Senhor, ao contrário, não valendo-se sumariamente de suas prerrogativas legítimas como soberano de toda a terra, autenticou a sua autoridade por meio de seu comportamento salvífico, refletido na liderança servidora de Moisés ao libertar o povo do Egito.

Grandes líderes da humanidade utilizaram a posição e o poder formal para mudar o destino de seus liderados. Se compararmos as figuras de Abraão Lincoln, Winston Churchill e Mikhail Gorbatchev, perceberemos facilmente que todos eles souberam utilizar o poder formal para se tornar benfeitores da humanidade. Lincoln libertou seu país da escravidão e garantiu a unidade nacional, liderando e vencendo a guerra civil americana. Churchill garantiu a soberania e a preservação da Inglaterra na Segunda Guerra Mundial; e Gorbatchev mudou a história da União Soviética, pondo fim à ditadura comunista em seu país. Se olharmos a um segundo grupo de pessoas já julgado pela história, vamos perceber que Adolf Hitler, Sadam Hussein e Algusto Pinochet utilizaram a liderança formal para praticar o exercício abusivo do poder, cometendo crimes contra a humanidade com violações flagrantes dos direitos humanos. Hitler, em nome de um pretenso império alemão, assassinou seis milhões de judeus, além de fazer milhares de outras vítimas. Sadam governou o Iraque massacrando e eliminando qualquer voz que discordasse ou fosse suspeita de discordar do seu regime; e Pinnochet manteve-se no poder chileno durante 17 anos à custa de torturas, mortes e 'desaparecimentos'. Em contraste com os exemplos acima mencionados, podemos perguntar: 'o que têm em comum Mahatma Gandhi, Madre Teresa de Calcutá, e Nelson Mandela?'. A resposta é simples: 'Os três tiveram influência e autoridade moral incontestáveis; independentemente de qualquer tipo de poder formal'. Gandhi, que jamais foi eleito para uma função pública, mudou a história da Índia liderando um movimento de resistência absoluta ao domínio britânico de forma pacífica, sem jamais derramar uma só gota de sangue. Madre Teresa construiu um império de caridade e assistência social, comprometendo-se pessoalmente com os pobres e sofredores. Nelson Mandela mudou a história da África do Sul, liderando a luta contra a opressão racista do Apartheid. Destituído de qualquer poder formal, Mandela transformou a história ao longo dos 27 anos em que ficou atrás das grades de uma prisão, de onde saiu para se tornar o primeiro presidente negro do país. Os 
exemplos anteriores indicam que, apesar de intimamente relacionados, liderança e poder não são necessariamente a mesma coisa. Se, em alguns casos, liderança se confunde com o poder formal, em outros, independe totalmente dele. Há líderes que se tornam grandes pela posição formal, enquanto outros destacam-se como pessoas que exercem autoridade moral sem que tenham ou não qualquer posição formal (MARINHO, 2011, p. 20, 21).

Ainda que os exemplos e seus contextos acima apresentados possam, em certa medida - devido a ambiguidade humana permear a história -, ser passíveis de interpretação, o que se quis extrair deles foi a questão relativa à legitimidade do poder. Das três categorias apontadas, a terceira parece ser digna de maior honra, embora a primeira seja, até certo ponto, reputada como positiva. Isso porque, a dissociação do comportamento de qualquer ambição de poder realça os interesses legitimamente preocupados com o bem do próximo.

Nesse sentido, portanto, é que a religião - detentora da herança sapiencial das antigas narrativas da Bíblia Hebraica -, apoiada por competentes estudos acadêmicos, precisa exercer seu dever de opor-se a sistemas de poder que dão sinais de repetir atrocidades condenadas tanto no mundo narrado na Bíblia, quanto na história recente da humanidade. Discursos que propagandeiam o desprezo aos estrangeiros, reputando-os como elemento de risco a soberania nacional, quer seja por razões religiosas ou motivos financeiros, precisam ser denunciados como antibíblicos, ainda que, e principalmente quando pretensamente fundamentados nas Escrituras Sagradas. No âmbito da narrativa exodal, o poder de faraó foi ilegitimado por sua própria conduta injusta e opressora. Assim, também, hoje comportamentos dessa natureza precisam ser veementemente rechaçados.

\section{Referências bibliográficas}

ALTEMEYER JUNIOR, Fernando. Filhos de Abraão, nosso pai na fé. In: BAGGIO, Fábio; PARISE, Paolo; SANCHEZ, Wagner L. (Coords.). Mobilidade humana e identidades religiosas. São Paulo: Paulus, 2016. p. 191-197.

ALTER, Robert. The art of biblical poetry. 2. ed. New York: Basic Books, 1985.

BAR-EFRAT, Shimon. Narrative art in the Bible. 2. ed. New York: T\&T Clark, 2008.

BARTOR, Assnat. Reading Law as narrative: a study in the casuistic laws of the Pentateuch. Atlanta: Society of Biblical Literature, 2010.

BERLIN, Adele. Introduction to hebrew poetry. In: DORAN, Robert et al. (Eds.). The new interpreter's Bible. V. 4. Nashville: Abingdon Press, 1996. 
BREY, Marcela B. A religião como bem humano básico: uma análise do papel da igreja na proteção dos direitos fundamentais das minorias. In: CONGRESSO INTERNACIONAL DE DOUTRINA SOCIAL DA IGREJA, 3.; SIMPÓSIO INTERNACIONAL DO PEPG EM TEOLOGIA DA PUC-SP, 4.; CONGRESSO BRASILEIRO DE TEOLOGIA MORAL, 43., 2018, São Paulo. Os Direitos Humanos à luz da Doutrina Social da Igreja. (Anais eletrônico). ARAUJO, Gilvan Leite de; GRENZER, Matthias (Orgs.). São Paulo: PUC-SP; UNISAL, 2018a, p. 15-21. Disponível em: <https://www.pucsp.br/sites/ default/files/download/posgraduacao/programas/teologia/anais-texto-final-13-12-2018. pdf>. Acesso em: 27 dez. 2018a.

BREY, Petterson. Direitos e deveres de um Reino de Sacerdotes em face ao Direito Humano básico à instrução: abstrações do discurso do Senhor no Monte Sinai (Ex 19,37). In: CONGRESSO INTERNACIONAL DE DOUTRINA SOCIAL DA IGREJA, 3.; SIMPÓSIO INTERNACIONAL DO PEPG EM TEOLOGIA DA PUC-SP, 4.; CONGRESSO BRASILEIRO DE TEOLOGIA MORAL, 43., 2018, São Paulo. Os Direitos Humanos à luz da Doutrina Social da Igreja. (Anais eletrônico). ARAUJO, Gilvan Leite de; GRENZER, Matthias (Orgs.). São Paulo: PUC-SP/UNISAL, 2018b, p. 166-173. Disponível em: <https:/www.pucsp.br/sites/default/files/download/posgraduacao/programas/ teologia/anais-texto-final-13-12-2018.pdf>. Acesso em: 19 dez. 2018 b.

BREY, Petterson. O primeiro discurso direto do Senhor no Sinai: um estudo literário-teológico de Ex 19,3-7. 2019. 211 f. Dissertação (Mestrado em Teologia) - Programa de Estudos Pós-Graduados em Teologia, Pontifícia Universidade Católica de São Paulo, São Paulo, 2019. Disponível em: <https://tede2.pucsp.br/handle/handle/22112>. Acesso em: 28 jul. 2019.

BROWN, Gillian; YULE, George. Discourse analysis. New York: Cambridge University Press, 2012.

CASSUTO, Umberto. A commentary on the Book of Exodus. Jerusalem: The Magnes Press; The Hebrew University, 1967.

CHILDS, Brevard S. Exodus: a commentary. (Old Testament Library). London: SCM Press, 1991.

CRÜSEMANN, Frank. A Torá: teologia e história social da lei do Antigo Testamento. Trad. Haroldo Reimer. 2. ed. Petrópolis: Vozes, 2002.

DOZEMAN, Thomas B. Commentary on Exodus. (The Eerdmans Critical Commentary). Grand Rapids: William B. Eerdmans Publishing, 2009.

DURHAM John I. Exodus. (Word Biblical Commentary). V. 3. Dallas: Word, Incorporated, 1987.

FERNANDES, Leonardo A.; GRENZER, Matthias. Exxodo 15,22-18,27. (Comentário Bíblico Paulinas). São Paulo: Paulinas, 2011.

FISCHER, Georg; MARKL, Dominik. Das Buch Exodus. (Neuer Stuttarter Kommentar Altes Testament). Stuttgart: Verlag Katholisches Bibelwerk GmbH, 2009.

FOKKELMAN, Jan P. Exodus. In: ALTER, Robert; KERMODE, Frank (Eds.). The literary guide to the Bible. Cambridge: The Belknap Press of Harvard University Press, 1987. 
GRENZER, Matthias. O projeto do êxodo. 2. ed. São Paulo: Paulinas, 2007.

GRENZER, Matthias. O fracasso da política de opressão violenta (Êxodo 1,8-14).

Horizonte: Revista de Estudos de Teologia e Ciências da Religião, Belo Horizonte, v. 12, n. 33, p. 141-163, jan.-mar. 2014a. Disponível em: < https://doi.org/10.5752/P.21755841.2014v12n33p141-163>. Acesso em: 27 out. 2018.

GRENZER, Matthias. O grito dos oprimidos (Ex 2,23-25). Revista de Teologia e Ciências da Religião da UNICAP, Recife, v. 4, n. 1, p. 19-34, dez. 2014b. Disponível em: $<$ https://doi.org/10.25247/2237-907x.2014v4n1.p319-334>. Acesso em: 29 out. 2018.

GRENZER, Matthias. A proposta ímpar do amor ao imigrante (Lv 19,33-34). In: MOREIRA, Alberto da S. (Org.). Religião, migração e mobilidade humana. Goiânia: Editora da PUC Goiás, 2017, p. 13-30.

GRENZER, Matthias; BREY, Petterson. Águia ou abutre? (Ex 19,4). Revista de Cultura Teológica, São Paulo, v. XXV, n. 90, p. 347-360, jul.-dez. 2017. Disponível em: $<$ https://doi.org/10.23925/rct.i90.35981>. Acesso em: $31 \mathrm{dez} .2017$.

HOUTMAN, Cornelis. Exodus. (Historical Commentary on the Old Testament). V. 2. Leuven: Peeters Publishers, 1996.

KESSLER, Rainer. Die Ägyptenbilder der Hebräischen Bibel: ein Beitrag zur neueren Monotheismusdebatte. (Stuttgarter Bibelstudien 197). Stuttgart: Verlag Katholisches Bibelwerk GmbH, 2002.

LONGACRE, Robert E. The grammar of discourse. 2. ed. New York: Plenum Press, 1996.

MARGUERAT, Daniel; BOURQUIN, Yvan. Pour lire les récits bibliques: initiation à l'analyse narrative. 4. ed. Paris; Genève: Les Éditions du CERF; Labor et Fides, 2009.

MARINHO, Robson M. Liderança em Teoria e Prática. In: OLIVEIRA, Jayr F.; MARINHO, Robson M. (Orgs.). Liderança: uma questão de competência. São Paulo: Saraiva, 2011, p. 9-22.

MILLER, Cynthia L. Introducing direct discourse in biblical hebrew narrative. In:

BERGEN, Robert D. (Ed.). Biblical hebrew and discourse linguistics. Dallas: Summer Institute of Linguistics, 1994.

MOREIRA, Alberto da S. Violência, conflitos religiosos e mobilidade humana. In:

MOREIRA, Alberto da S. (Org.). Religião, migração e mobilidade humana. Goiânia:

Editora da PUC Goiás, 2017.

PIXLEY, George V. Exodo. Trad. J. Rezende Costa. São Paulo: Paulinas, 1987.

PROPP, William H. Exodus 19-40: a new translation with introduction and commentary. (The Anchor Bible Commentary). V. 2A. New York: Doubleday, 2006.

ROBBINS, Vernon K. Exploring the texture of text: a guide to socio-rhetorical interpretation. Harrisburg: Trinity Press International, 2012.

SARNA, Nahum M. Exodus commentary. (The JPS Torah Commentary). Philadelphia; New York; Jerusalem: The Jewish Publication Society, 1991. 
SKA, Jean L. Sincronia: l'analisi narrativa. In: SIMIAN-YOFRE, Horácio. (Org.). Metodologia dell'Antico Testamento. Bologna: Edizioni Dehoniane Bologna, 2009. p. 139-170.

USARSKI, Frank. A dinâmica entre migração e religião e o capital analítico da Ciência da Religião: reflexões sobre o estado da arte e desafios contemporâneos. In: BAGGIO, Fábio; PARISE, Paolo; SANCHEZ, Wagner L. (Coords.). Mobilidade humana e identidades religiosas. São Paulo: Paulus, 2016, p. 63-84.

Submetido em: 1-9-2019

Aceito em: 25-10-2019 